\title{
Ahora que estamos juntas: memorias, políticas y emociones feministas
}

\author{
Claudia Andrea Bacci' (iD) 0000-0002-8012-1114 \\ 'Universidad de Buenos Aires, Facultad de Ciencias Sociales, Instituto de Estudios de \\ América Latina y el Caribe, Buenos Aires, CABA, Argentina. C1122AAJ - \\ iealc@sociales.uba.ar
}

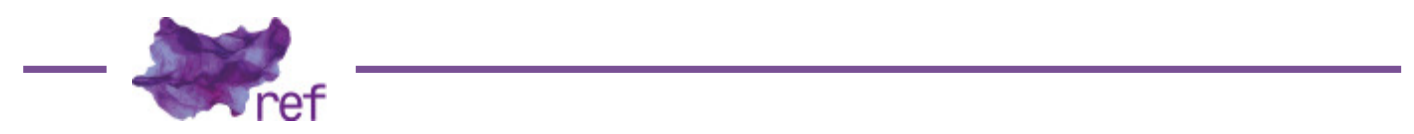

Resumen: Este trabajo desarrolla algunos aspectos del repertorio afectivo feminista que históricamente cruza la política y la teoría feminista, en el marco de una reflexión más general sobre el presente de los feminismos en América Latina. Después de una breve introducción que contextualiza la importancia crítica de las emociones y los recuerdos en la reinvención de la política feminista, se abordan algunos debates y diálogos sobre el problema de la disparidad, el conflicto y las diferencias entre las mujeres como obstáculos y elementos constitutivos de los feminismos desde la década de 1970 y 1980 s. Se analizan las figuras de la hermandad (sisterhood), la sororidad y la práctica de la diferencia sexual, cada una de las cuales caracteriza diferentes momentos y debates de los feminismos de los siglos XX y XXI.

Palabras clave: práctica de la diferencia sexual; sororidad; hermandad entre mujeres; feminismos.

Agora que estamos juntas: memórias, políticas e emoçōes feministas

Resumo: Este trabalho desenvolve alguns aspectos do repertório afetivo feminista que historicamente atravessa a política e as teorias feministas, no quadro de uma reflexão mais geral sobre o presente dos feminismos na América Latina. Após uma breve introdução que contextualiza a importância crítica das emoções e memórias na reinvenção da política feminista, alguns debates e diálogos sobre o problema da disparidade, conflito e diferenças entre mulheres são abordados como obstáculos e elementos constitutivos do feminismo desde as décadas de 1970 e 1980. São analisadas as figuras de irmandade (sisterhood), sororidade e prática da diferença sexual, cada uma das quais caracteriza diferentes momentos e debates dos feminismos dos séculos XX e XXI.

Palavras-chave: prática da diferença sexual; sororidade; irmandade entre mulheres; feminismos.

Now that We are Together: Memories, Politics, and Feminist Emotions

Abstract: This work develops some aspects of the feminist affective repertoire that historically crosses feminist politics and theory, within the framework of a more general reflection on the present of feminisms in Latin America. After a brief introduction that contextualizes the critical importance of emotions and memories in the reinvention of feminist politics, some debates and dialogues about the problem of disparity, conflict and differences between women are addressed as obstacles and constitutive elements of feminisms since the 1970s and 1980s. The figures of sisterhood, sorority and the practice of sexual difference are analyzed, each of which characterizes different moments and debates of feminisms of the twentieth and twenty-first centuries.

Keywords: Practice of Sexual Difference; Sorority; Sisterhood; Feminisms.

\section{Memorias, políticas y emociones feministas}

iPoder, poder / poder popular! Luchar con la compañera / le gusta a usted, le gusta a usted iY ahora que estamos juntas! / iY ahora que sí nos ven! iAbajo el patriarcado, se va a caer, se va a caer! iArriba el feminismo que va a vencer, que va a vencer! (ANÓNIMO, Canción de protesta feminista, Argentina, 2015) 
La cuestión de la negación o la expulsión de las diferencias entre las feministas es casi tan temprana como el mismo feminismo, atravesado por disputas, acusaciones y debates en torno a una definición acerca de su/s política/s que, hasta el presente, resulta imposible. De este modo, la cuestión de la diferencia y las emociones en torno a esta resultan nodales para los feminismos contemporáneos, a la vez que son fuente de incomodidad e inestabilidad política. La unidad entre las feministas constituye un problema a ser repensado en cada contexto.

En la última década asistimos en América Latina a una profusión de marchas y campañas que tomaron las calles por sorpresa para gritar la indignación por la expansión e incremento de la crueldad hacia las mujeres. Por ejemplo, las movilizaciones masivas en la Argentina denunciaron en 2015 bajo la consigna \#NiUnaMenos, la inacción estatal ante los feminicidios, sobre los cuales los medios de comunicación inundaban la escena pública con relatos e imágenes espectaculares de horror y misoginia. Protestas similares - aunque no necesariamente conectadas - se derramaron por el continente, se articularon internacionalmente y escalaron en la masividad de participantes y en la complejidad de sus consignas hasta llegar a los Paros Feministas Internacionales del último 8 de marzo que proclamaban un "feminismo sin fronteras" (AA.W., 2019). En el llamamiento a este último Paro, el Colectivo Ni Una Menos (2019) de Argentina apostaba a la composición de "sentidos, tiempos, espacios y prácticas" en la denuncia del hartazgo "de abusos, femicidios y travesticidios, pero también para tramar una nueva forma política contra el fascismo global, contra la feminización de la pobreza y por aborto legal, seguro y gratuito".

La expansión transversal de las consignas al ritmo de la indignación feminista ha sufrido apropiaciones que redireccionan la propuesta feminista hacia formas de subjetivación ligadas al nuevo despliegue del neoliberalismo en América Latina que articulan libertad (de mercado) y autogestión (de la vida) por medio de discursos de la economización de todas las esferas de la vida (Wendy BROWN, 2015). Una de las formas de estas políticas de subjetivación son las propuestas dirigidas a desarrollar el 'carácter emprendedor' o 'emprendedorismo', que recurre a discursos críticos como el feminismo y la noción de sororidad para fundamentar la fragilización de la vida colectiva (crisis de vivienda y salud, tareas de cuidado de las infancias y personas adultas mayores, enfermas, etc.). Por eso, como apunta Joan W. Scott, es central una operación crítica a la hora de abordar las emociones y las memorias en la reconstrucción histórica tanto como en la reinvención de la política feminista, una operación analítica que "utiliza el pasado para interrumpir las certezas del presente y, por lo tanto, abre el camino para imaginar un futuro diferente" (Joan W. SCOTT, 2011 , p. 33-34, mi traducción). ${ }^{1}$

Un ejemplo de este tipo de abordajes lo encarna el trabajo de Sara Ahmed (2014) en torno a La política cultural de las emociones. Entre otras formas de la emoción que circulan y dan forma a nuestro presente, la autora analiza la "indignación feminista" como "una respuesta emocional, así como ética y política" a experiencias dolorosas de violencia y discriminación, a la vez que advierte acerca de la fetichización y universalización de estas experiencias como base ontológica para la política (feminista) que muchas veces sostiene la idea de una "solidaridad entre mujeres", algo que puede "funcionar para deslegitimar los intentos feministas para entender la complejidad de la vida social y psíquica" (AHMED, 2014, p. 263). Desde su perspectiva, el feminismo no puede reducirse a la indignación que lo moviliza, pero la indignación es también la que produce conocimiento sobre el dolor de la experiencia, agrega Ahmed, siguiendo el pensamiento de Audre Lorde. Es la indignación la que nos permite hacer una traducción de la injusticia del mundo en que vivimos y darle el nombre de sexismo, racismo, discriminación, homo/transfobia, y se constituye así en un acto de habla dirigido a otras/otros que deben/pueden responder. Las feministas indignadas nos convertimos en "aguafiestas" por señalar esas injusticias, y sabemos que "aguar la fiesta" se refiere a una forma de intervenir que es recibida como controversial, que molesta o fastidia, porque "cuando ella habla, parece enervada [...] tensa las cosas" (AHMED, 2018, p. 61), "está dispuesta a causar infelicidad" (p. 348).

Para ser escuchadas, las feministas gritamos la indignación, pero aquello contra lo cual gritamos no es ajeno al feminismo, como señalaron las mujeres negras que se acercaban al feminismo denunciando el racismo que subyacía en él. Al desconocer lo que diferencia, la indignación y el dolor se trastocan y se vuelven interiores al propio feminismo, socavando su supuesta "unidad". Este ideal de unidad, señala también Ahmed (2014, p. 269-270), esconde en verdad un impulso a la homogeneización y reificación de objetivos y formas de lucha política, a la expulsión de la incomodidad y a la restricción dentro del feminismo, que se convierte entonces en un movimiento con puertas de acceso y carnets de identidad para "nativas", un feminismo que se vuelve excluyente. ¿Quiénes y cómo serían las 'verdaderas' feministas? ¿Y cómo juegan las ideas de unidad y de diferencia en esas definiciones?

\footnotetext{
' La traducción de todos los textos citados del original en otros idiomas me pertenece. Quiero agradecer a quienes evaluaron este artículo por sus valiosas sugerencias e indicaciones, las cuales fueron incorporadas siempre que fue posible.
} 
Con el objetivo más general de explorar el modo en que la emergencia de la diferencia atraviesa históricamente a los feminismos occidentales, en este artículo exploro algunos ejes de las memorias, políicas y emociones feministas que enmarcan algunos de los debates sobre la política feminista del presente en América Latina. Para ello retomo tres figuras que caracterizan al feminismo occidental (Chandra T. MOHANTY, 2003, p. 106-124), como son la hermandad entre mujeres pensada por el feminismo radical estadounidense en los 60 , así como su reformulación más reciente en nuestra región (sororidad), y la práctica de la diferencia sexual formulada por el feminismo italiano en los años 70-80.

En primer lugar, presentaré algunas escenas relativas a las acciones y manifestaciones feministas del presente, en las que una serie de imágenes y memorias políticas se apropian y reformulan los vínculos políticos feministas donde las nociones de diferencia y de genealogía resultan fundamentales para la acción política en el Cono Sur de América Latina.

En segundo lugar, planteo algunas de las paradojas y obstáculos teórico-políticos en torno a la noción de 'diferencia' que surgen ante los intentos de definir el sujeto del feminismo. Este apartado aborda tres formas de la política afectiva y vincular de los feminismos desde los años 60, como son la 'hermandad' (entre mujeres o sisterhood), la sororidad y la práctica de la diferencia sexual. Para ello recorro primero aspectos centrales de la noción de hermandad (entre mujeres) formulada por el feminismo radical estadounidense, como una forma presente de lo que Scott caracteriza como una "fantasía melancólica" propia del feminismo en su evaluación del pasado del movimiento. Luego trato la noción de sororidad, de enorme difusión durante la última década, cuyo carácter ético propone prácticas de cuidado frente a las diversas formas de violencia contra las mujeres, sexual y de género. Finalmente, en la tercera parte de este apartado, recorro algunos de los planteos de las feministas italianas desde los años 70 y 80 sobre el problema de la disparidad, el conflicto y las diferencias entre las mujeres, y su propuesta de una práctica política de la diferencia sexual. Las reapropiaciones y reformulaciones de estas nociones feministas se convierten en lentes a través de los cuales observar las tensiones y paradojas del presente político feminista.

\section{Anacronismos virtuosos}

Me referiré en primer lugar al trabajo realizado desde el Archivo Oral de Memoria Abierta (2012) en base a entrevistas audiovisuales de sobrevivientes y familiares de personas detenidasdesaparecidas en mi país durante la última dictadura militar (1976-1983). Entre 2010 y 2012 , desde el equipo de investigadoras nos propusimos revisar los testimonios tomados desde la creación del Archivo en 2001 y producir nuevos testimonios para abordar los relatos sobre la violencia sexual durante aquel periodo. Además de visibilizar estas formas de violencia, esperábamos mostrar que, pese a la falta de escucha judicial y social, las sobrevivientes habían testimoniado en distintas ocasiones, y con diferentes objetivos, no solo la denuncia ante la justicia y los medios, sino también para la reconstrucción de lazos de confianza y la reparación simbólica a partir de la reelaboración de memorias que consideraran este sufrimiento como legítimo. Hablar con las vecinas, las profesionales de salud, familiares, amistades y compañeros de militancia y cautiverio importaba tanto como la justicia.

Sin embargo, muchas de las entrevistadas se referían a esos intentos de narrar como fallidos, al silenciamiento y la deslegitimación de su palabra en público. Esta 'sordera social' era un efecto de la no-receptividad o el rechazo abierto del contexto social, de la dificultad para actualizar la noción de derechos humanos al interior del propio movimiento y de las izquierdas, a la percepción negativa de las acciones de la justicia y, de manera no menor, a las condiciones de la enunciación relativas a las etapas de la vida de las mujeres afectadas: ¿cómo y cuándo hablarle de esto a sus hijas e hijos, parejas, madres-padres? Además, esta 'sordera social' también se desplaza y cambia, en particular de la mano del activismo feminista en las calles.

Alejandra Oberti (2019) indaga en las relaciones entre las políticas feministas y de derechos humanos durante los años ' 80 y señala que, si bien ambos movimientos participaron de la reconstrucción democrática, la tarea de reconstruir una genealogía que trace puentes entre uno y otro no puede ignorar las tensiones y desencuentros entre ambos. Mientras el movimiento feminista argentino se reconoció rápidamente en el movimiento de derechos humanos, en sus organizaciones y actores centrales (Madres y Abuelas de Plaza de Mayo, sobrevivientes y ex militantes, etc.), un interlocutor legítimo en la denuncia de la violencia contra las mujeres y en las consignas en favor de una mayor democratización social y política, señala Oberti, lo inverso no siempre ha sido el caso, al menos hasta muy recientemente.

Estas coaliciones transversales y transgeneracionales se encuentran potencialmente disponibles para el conjunto de movimientos sociales que manifiesta y protesta, listas para ser actualizadas en cada presente, como un hilván rojo en el revés de la escena pública, entretejiendo acciones y referencias que son citadas y recolocadas en nuevos contextos.

Para referirse a esta forma de la transmisión feminista, Scott recurre a las figuras del 'eco' y la 'reverberación' (2011) como estrategias de mirada crítica hacia los feminismos, donde la fantasía 
- transformada en herramienta analítica de lectura a contrapelo - produce nuevas miradas sobre la historia del feminismo (feminist history) y reformula su presente, sus repertorios de protesta y las historias que nos cuenta. Mientras la figura del 'eco' apunta a los modos en que las políticas feministas se transmiten y transforman a través del espacio y del tiempo (SCOTT, 201 1, p. 45-67), la 'reverberación' delinea el modo en que circulan y se conectan estrategias y conceptos feministas cuyos sentidos se adaptan y transforman en diferentes contextos, generando solidaridades anacrónicas que reacomodan la unidad (siempre ficticia) entre las mujeres (p. 68-90). Esta operación crítica produce puentes impensados en las prácticas políticas contemporáneas y en la construcción de memorias, actualizándolas a la vez que reconstruyen sus propias genealogías en el espacio público. Voy a recuperar tres imágenes de lo que llamaré un 'anacronismo virtuoso' para mostrar el modo en que operan estos ecos y reverberaciones.

Un ejemplo de este tipo de transformaciones en la discursividad social en la Argentina surge a partir del trabajo de la Campaña Nacional por el Aborto Legal, Seguro y Gratuito en la instalación del debate parlamentario de 2018 sobre la despenalización y legalización del aborto, que puso en primer plano el carácter social de la violencia contra las mujeres y suscitó que muchas mujeres hablaran de sus abortos por primera vez en sus vidas. Emergieron entonces otras tramas entre-mujeres que impulsaron el compromiso con la lucha feminista en las calles, graficado en las articulaciones de los símbolos del movimiento por los derechos humanos y de la Campaña, los pañuelos blanco y verde respectivamente (Nayla Luz VACAREZZA, 2019).

En ese marco, el 12 de septiembre de 2018, Stella Hernández, ex-presa política y sobreviviente del centro clandestino de detención (CCD) del Servicio de Informaciones de la Jefatura de la Policía de Santa Fe, declaró por tercera vez en un juicio por crímenes de lesa humanidad, en lo que se conoce como 'causa Feced' iniciada en los inicios de la transición democrática argentina (MEMORIA ABIERTA, 2012, p. 39-40; p. 90-91). Hernández también fue entrevistada en 2011 para el Archivo Oral mencionado (MEMORIA ABIERTA, 2011), donde narró su secuestro y cautiverio en ese CCD en 1977, destacando que su primera denuncia por violencia sexual la presentó allí mismo, durante su cautiverio, ante los jefes del grupo de torturadores, refrendándola luego en 1984 ante la CONADEP.

En su última declaración judicial, al salir del Tribunal, Hernández dijo a los distintos medios periodísticos que declaraba "por la lucha de las mujeres de hoy, de ayer y de siempre." La foto del periódico Página 12 (2018) la muestra a la salida, saludando con la "V" de la victoria y con el pañuelo verde de la Campaña Nacional por el Aborto atado a su muñeca izquierda. En su breve mensaje, dijo que "Este pañuelo además de ser un símbolo, es la síntesis de la lucha y resistencia de las mujeres en los sótanos, durante la dictadura militar. [...] La palabra sororidad, aplica muy bien, porque nos cuidábamos entre nosotras para sobrevivir" (PÁGINA 12, 2018). La política callejera en favor del aborto de esos meses potenciaba una mirada retrospectiva a la violencia contra las mujeres en la dictadura, resignificando las estrategias de supervivencia y apoyo mutuo como una forma de solidaridad entre-mujeres que, desde el presente, podía ser leída como "feminista".

Una segunda imagen anacrónica se produjo durante el $33^{\circ}$ Encuentro Plurinacional de Mujeres, Lesbianas, Travestis y Trans + que tuvo lugar en La Plata (Buenos Aires) en octubre de 2019. Allí integrantes de la agrupación H.I.J. ?.S." realizaron la mesa redonda "El linaje de nuestras luchas: las militantes de los 70, las Madres y Abuelas de Plaza de Mayo, el \#NiUnaMenos y los escraches", precedida por una acción callejera con carteles donde las clásicas fotos en blanco y negro de los rostros de mujeres detenidas-desaparecidas eran intervenidas con pañuelos verdes y violetas. En su convocatoria se reconocían como "Ias nietas de las Madres y las Abuelas de Plaza de Mayo. Somos las hijas de las compañeras que nunca pudieron callar. Somos las herederas de un linaje de lucha, amor y resistencia". Algunas de las integrantes señalaron que su participación en las movilizaciones de \#NUM y en los reclamos por el aborto, antes aun de organizarse como "HIJAS en H.I.J.O.S", las llevó también a pensar modos de confrontar los micromachismos y el sexismo dentro de su propia organización.

Como afirma Lilian Celiberti (2015), una mirada desde el género sobre las memorias supone recuperar no solo aquellas experiencias que pueden ser nombradas y resignificadas desde los conceptos y análisis feministas, sino que resignifica todas las dimensiones de la experiencia de las mujeres en sus comunidades y grupos de pertenencia. Así, estas escenas representan un giro, donde el reconocimiento de los vínculos entre mujeres fundados en formas de solidaridad sui generis establecen genealogías que producen anacronismos virtuosos, temporalidades desfasadas que reconstruyen el campo discursivo de lo vivible.

Un último anacronismo, convertido en una acción viralizada en las redes sociales, surgió de la intervención feminista situada en un conflicto específico y articula también las luchas por los derechos humanos y los feminismos en la región. Me refiero a la performance del grupo de artistas

${ }^{2}$ Acrónimo de Hijos e Hijas por la ldentidad y la Justicia contra el Olvido y el Silencio, intervenido con el signo feminista (?). 
feministas Las Tesis (Valparaíso, Chile), Un violador en tu camino. Sin pretender un análisis detallado de las diferentes expresiones que tomó en los diferentes países y con sus diferentes activismos, ${ }^{3}$ en el Cono Sur las reformulaciones en la letra de la canción que estructura la coreografía de la performance tomó diferentes cuestiones, según el estado de los debates locales. Iniciada en Valparaíso el 25 de noviembre de 2019 - Día Internacional de la Eliminación de la Violencia contra las Mujeres -, como forma de protesta contra las violaciones y abusos sexuales cometidos por fuerzas de seguridad (Carabineros) durante la represión de las manifestaciones de octubre contra las políticas neoliberales del gobierno de Sebastián Piñera, pronto surgieron réplicas que señalaba la transversalidad generacional y étnica de estas violencias, estableciendo puentes con las mujeres militantes políticas de los 70 y sobrevivientes de la cárcel política de la dictadura de Pinochet, así como con las mujeres mapuches en su traducción al mapudungún en Temuco. En Argentina, su apropiación introdujo el reclamo por la despenalización y legalización del aborto; en Perú, se replicó en quechua (Cusco); en Brasil, se agregó la pregunta "¿Quem matou Marielle [Franco]? Seu legado está presente!" (Florianópolis).

Los ecos entre espacios en un mundo que se pretende global, o entre generaciones, como en las intervenciones de las HIJAS argentinas, y las reverberaciones que surgen a partir de la performance de Las Tesis que se conectan con las memorias sobre la violencia sexual de las ex presas políticas chilenas, 'acuerpan' los legados del movimiento de mujeres y los feminismos en sus luchas contra las violencias y los discursos de odio centrados en el género, y permiten imaginar de otro modo coaliciones entre diferentes luchas y generaciones, llevando las consignas y las historias más allá de sí mismas para establecer genealogías feministas activas. Los préstamos no ocultan las tensiones o desencuentros, sino que nos obligan a leer con lentes multicolores - verdes, violetas, naranjas - las citas, las imágenes, los gestos y las palabras como 'sororidad'.

\section{La casa de la diferencia: ¿Una historia del feminismo?}

Diversas miradas críticas a las historias del feminismo recomponen trayectorias y debates dentro de un marco de inteligibilidad que pone en discusión las 'olas sucesivas', señalando que este modelo privilegia una genealogía eurocéntrica y estadounidense que se presenta como universal y progresiva, y desconoce diferentes temporalidades en otras regiones (Victoria BROWNE, 2014; MOHANTY, 2003, p. 43-80). Una temporalidad feminista desde el Cono Sur, por ejemplo, requeriría solapar las olas y confundir las décadas de acuerdo con los impasses de las dictaduras en los diferentes países (cada uno con su propia temporalidad y condiciones), y sobre todo actualizar las discusiones específicas que lo travesaron en diferentes momentos (Sonia ÁLVAREZ, 2019). Los casos de Brasil, Chile y Argentina pueden servir de ejemplos que desacomodan la historia hegemónica de las 'olas' sucesivas, así como las articulaciones y debates tal como se dieron en el Hemisferio Norte, e incluir en el recuento el peso de las agendas transnacionales desde los 90 (Silvia CHEJTER, 1996; Sueli CARNEIRO, 2019; Mónica TARDUCCI; Catalina TREBISACCE; Karin GRAMMÁTICO, 2019; Luna FOLLEGATI, 2018; Cidinha DA SILVA, 2018; Cynthia A. SARTI, 2004).

En su libro sobre las historias que (se) relatan las teóricas feministas occidentales, Clare Hemmings (2018) analiza las gramáticas políticas que estas historias construyen al narrarse, delineadas a partir de narrativas de progreso, de pérdida y de retorno al feminismo. Estas historias contienen aspectos subrepresentados, silencios y omisiones, donde resaltan tanto el rechazo a las teorías fundadas en una ontología de la diferencia sexual - sea en sus vertientes estructuralista o culturalista - como los desafíos persistentes a la unidad por parte de feministas negras y chicanas, entre otras. Así, señala esta autora, los relatos de progreso, pérdida o retorno en la teoría feminista occidental suponen un pasado de unidad y colocan en la noción de 'diferencia' (en su ontologización) tanto un hito como un obstáculo.

Scott (2012) plantea también la difícil paradoja que atraviesa la historia del pensamiento feminista occidental desde que las revolucionarias francesas del siglo XVIII denunciaron la exclusión de las mujeres de la noción de 'individuo'. La autora resume esta paradoja como "la necesidad de aceptar y de rechazar al mismo tiempo la 'diferencia sexual'” (SCOTT, 2012, p. 20), una tensión irresuelta entre el reclamo planteado 'como mujeres' (diferencia sexual) por ser incorporadas en el universal político del 'ciudadano' (igualdad política). Para la autora, la 'diferencia sexual' de las mujeres no radicaría en una distinción biológica u ontológica sino que constituye una matriz de inteligibilidad y significación de la producción/reproducción histórica de las relaciones sociales diferenciadas por género, una articulación de relaciones de poder que atraviesa el modo en que definimos esta 'diferencia' en términos sexuados en diferentes esferas de las relaciones sociales (el trabajo, la política, los derechos, la familia, etc.) y cuyos efectos son contextuales y contingentes.

En este sentido, al analizar el derrotero de la historia del feminismo en la academia estadounidense, Scott muestra los efectos de esta perspectiva, tanto en la producción histórica

${ }^{3}$ Desarrollo un análisis sobre la performance de Las Tesis y algunas de sus múltiples replicaciones en el Cono Sur, en un artículo a ser publicado en el que indago diferentes expresiones de protesta sobre la violencia sexual y contra las mujeres en la región. 
como en la construcción política feminista:

'Mujeres', aunque modificada, parecía una excesiva universalización de las mujeres blancas, occidentales y heterosexuales, una categoría que no era lo suficientemente amplia como para hacer sola el trabajo que requirieron las consideraciones de las diferencias entre las mujeres. La aparición de nuevos movimientos políticos parecía requerir nuevos tipos de sujetos políticos; las identidades singulares ya no funcionaban como antes para la construcción de alianzas estratégicas múltiples y mutables. (SCOT, 2011, p. 38)

De manera similar Audre Lorde (2009) resaltaba ya en 1982 que era crucial enunciar y atender a la pregunta acerca de cómo considerar la cuestión de la diferencia en la política feminista:

Ser mujeres juntas no era suficiente. Éramos diferentes. Ser chicas gay juntas no era suficiente. Éramos diferentes. Ser Negras juntas no era suficiente. Éramos diferentes. Ser mujeres Negras juntas no era suficiente. Éramos diferentes. Ser tortilleras Negras juntas no era suficiente. Éramos diferentes. [...] Tardé mucho tiempo en darme cuenta de que nuestro lugar era el hogar mismo de la diferencia más que la seguridad de cualquier diferencia en particular. (LORDE, 2009, p. 377-378, itálicas en el original)

La memoria de la emergencia de la diferencia entre las mujeres que trae Lorde pone en cuestión la propia idea de que 'estar juntas' sea una solución a los disensos y el conflicto interno. Si la diferencia ha atravesado ese 'hogar' que agrupaba y cobijaba entonces, afirma Lorde, la diferencia es nuestra casa, la casa del feminismo.

Así, una reflexión sobre el proyecto feminista implica interrogarse en primer lugar cómo "las mujeres pueden estar en relación entre sí. Es un proyecto, porque todavía no hemos llegado a este punto" (AHMED, 2018, p. 30). Y si no estamos allí todavía es porque parte del problema consiste en este sujeto femenino del feminismo 'mujer', cuya inestabilidad emerge como un tema central casi desde los inicios de lo que se considera la 'segunda ola feminista' en los años 1970-1980. Ahmed retoma la genealogía de esos debates en presente y redobla la apuesta de su deconstrucción preguntándonos quiénes son esas mujeres que se enuncian como sujeto político del feminismo, quiénes somos el 'nosotras' bajo el cual nos cobijamos como feministas, qué dificultades hemos encontrado para integrarlo, para ser parte y permanecer, y cuál sería el trabajo necesario para reconocer ese sujeto plural en el momento mismo en que se constituye como tal, sin dejar de "cuestionar igualmente la instrumentalización del feminismo" (p. 32). Su respuesta -"[mujeres son] todas aquellas que viajan con la etiqueta de mujeres"- indica "una asignación (no solo un signo, sino también una tarea o un imperativo [...]) que puede conformarnos; hacernos; y rompernos." (p. 31-32), no está exenta de pasión y conflictos. Se trata entonces de narrar una historia feminista que (nos) incomoda.

\title{
Sisterhood: La irrupción de la diferencia
}

\author{
Y cuando nuestras hermanas gringas \\ amigas radicales nos ven \\ en carne viva \\ no como su propio retrato, \\ no están muy seguras \\ si \\ les encantamos tanto. \\ No somos tan felices como nos vemos \\ en \\ su \\ pared. \\ (Jo CARRILLO, "Y cuando se vayan, llévense sus retratos", 1988 [1979])
}

En el Diccionario de la Real Academia Española (2019), la palabra 'sororidad' tiene orígenes religiosos, del latín medievieval sororitas, 'congregación de monjas', y soror, 'hermana carnal', mientras que su traducción al inglés en Estados Unidos (sorority) remite a las asociaciones estudiantiles femeninas. El anglicismo sororidad traduce así a la "hermandad" entre mujeres, en contrapartida a la fraternidad (masculina), y da pie a otras dos definiciones que amplían los aspectos de género, como son la de "amistad o afecto entre mujeres" y la "relación de solidaridad entre las mujeres, especialmente en la lucha por su empoderamiento". Particularmente en esta última, podemos ver un desplazamiento hacia la política (la "lucha por empoderarse" de las mujeres) a partir de relaciones políticas basadas en la "solidaridad entre mujeres", algo diferente a la amistad o el afecto. Sabemos del peso normativo de la lengua en la construcción política del 
mundo y sus representaciones como para menospreciar este reconocimiento y legitimación del vocabulario feminista occidental del siglo XX por parte de la institución de la lengua española.

Sin embargo, la aceptación etimológica y su difusión masiva en el marco del creciente entusiasmo feminista al que asistimos puede velar una serie de debates en torno al contenido y el carácter de esta forma política del afecto y las relaciones entre mujeres/feministas, en una historia donde la cuestión de la diferencia tensiona de inmediato la unidad imaginaria de 'las sororas'. En este apartado recorreré un momento del pensamiento feminista que considero importante para comprender el presente de sus usos.

Pese al reconocimiento del diccionario, la palabra surgida en los inicios del pensamiento feminista radical estadounidense en los años 60, que definía la unión de intereses de las mujeres con los del movimiento feminista, es decir, las mujeres qua feministas, no fue sororidad (sorority) sino sisterhood (hermandad de/entre mujeres). En tanto apuesta a esta unidad, la hermandad de/entre mujeres pretendía diferenciarse de la asociación entre varones (fraternity) fundada en la universalización de sus privilegios y la negación de la segregación y discriminación socioeconómica y política que afectaba a las mujeres, al proletariado y a las personas racializadas por medio de instituciones como la esclavitud y la colonización. La noción surgió inicialmente de las críticas a la incapacidad de reconocer la subordinación de las mujeres al mismo nivel que la explotación y subordinación de clase por parte de las organizaciones de izquierda de las que participaban.

En su estudio sobre el surgimiento e historia del feminismo radical en los Estados Unidos, Alice Echols (1989) recupera estas críticas hacia las izquierdas y sectores progresistas de los 60 y 70 , que relacionan conciencia de clase y una conciencia de la común situación de las mujeres (sisterhood). Diferenciándose de las organizaciones de mujeres que continuaban la lucha por los derechos (civiles y políticos) de las sufragistas, las feministas que tomaron la escena política en los 60 privilegiaron la identidad como 'mujeres' y construyeron formas de politización centradas en la puesta en común de la experiencia femenina a través de la 'toma de conciencia feminista'. Esta primera forma de conciencia crítica del funcionamiento del orden social patriarcal vinculaba formas específicas de opresión hacia las mujeres - como la violencia sexual y la separación funcional de ámbitos y roles públicos y privados - arraigadas en instituciones como la familia nuclear y la heterosexualidad.

Una segunda forma de comprender y construir una política de la relación entre mujeres lo constituyó el trabajo de 'concienciación' desarrollado en pequeños grupos de mujeres que compartían lecturas, experiencias y sentimientos para fortalecer la solidaridad interna, como método de autoconocimiento, de organización y acción. En estos grupos, las participantes colocaban todas las teorías "bajo la prueba de la práctica de vida y la acción" a fin de evitar el "[desvío] hacia [la lucha por] reformas de un solo tema" y a la organización en torno a un objetivo único o principal, tal como consideraban había sucedido con la lucha sufragista, promoviendo la solidaridad y horizontalidad en las relaciones entre las participantes como base de la acción feminista (Kathie SARACHILD, 1970). ${ }^{4}$

La primacía de la experiencia y la práctica de la horizontalidad política resaltaba las similitudes entre las mujeres por sobre aquellas otras formas de opresión y subordinación como la clase o la raza y, como muestra Echols (1989, p. 101-203), privilegiaba la unidad interna y la expulsión de la propia idea de la diferencia entre experiencias particulares. La 'hermandad feminista' unía y volvía coherente un movimiento que nacía fragmentario, al costo de apagar las disidencias y suprimir el debate sobre la emergencia de liderazgos, omitiendo un debate abierto sobre la representación política.

Así, pese al crecimiento de los grupos feministas radicales durante los 60 , la negativa a considerar que la hermandad entre mujeres pudiera soportar la emergencia de diferentes formas de vivir y actuar como feministas, dio lugar a sucesivas rupturas que culminaron en la "erupción de la diferencia" y la fragmentación del movimiento y, según Echols, en la emergencia de un "feminismo cultural" que ataba aún más la condición femenina al sujeto político del feminismo 'mujer'.

Ann Snitow (2015) cuenta cómo llegó a hacerse feminista en 1969 y evoca que "La prisa particular que experimenté en esos primeros meses no pudo mantenerse por dos respiraciones. La hermandad se derrumbó con un toque, debilitada por las diferencias de raza, clase y tradiciones políticas, y también por los seres dañados y las 'lágrimas'" (SNITOW, 2015, p. 2). El derrumbe lo produjo una pregunta que atraviesa al feminismo y que acompaña la emergencia de otros sujetos feministas con experiencias diversas, nuevas reivindicaciones y potentes prácticas, planteada

\footnotetext{
${ }^{4}$ La propuesta de los grupos de concienciación o autoconciencia (consciousness-raising groups), desarrollada por Sarachild en 1968, fue publicada en diversas oportunidades en compilaciones feministas y retomada por autoras tan diversas como Catharine MacKinnon o Sheila Rowbotham. Sarachild (su nombre verdadero es Kathie Amatniek) integró el movimiento por los derechos civiles en los Estados Unidos a comienzos de los 60 en el Comité Coordinador Estudiantil No Violento (SNCC, siglas en inglés) y fue también quien formuló la consigna "La hermandad entre mujeres es poderosa" [Sisterhood is powerful!] en un volante distribuido en la manifestación de las mujeres contra la guerra de Vietnam organizada por la Brigada Jeannette Rankin en Washington el 15 de enero de 1968.
} 
por las feministas radicales lesbianas que cuestionaban la idea de la hermandad: "¿quiénes, preguntan, son 'nosotras'?" (SNITOW, 2015, p. 25).

Las cuestiones de la diferencia y la unidad de la lucha y el sujeto político no son exclusivas del feminismo en el siglo XX, pero atraviesan una de sus consignas más persistentes (Sisterhood is Powerful!). La hermandad entre mujeres (sisterhood), que las feministas radicales estadounidenses de fines de los 60 planteaban como eje de unidad y plataforma para la agencia política de/entre las mujeres, terminó siendo apropiado por sectores liberales del movimiento de mujeres que privilegiaban la igualdad (entre los sexos) y el 'empoderamiento' individual, despolitizando el carácter colectivo de la lucha feminista por la emancipación.

\section{¿Quiénes somos las sororas?}

En la revisión que realiza la antropóloga feminista mexicana Marcela Lagarde sobre el lugar central del feminismo en su vida, el sujeto feminista surge como apertura a la otredad entendida como margen del sujeto de derechos de la Modernidad-, con lo cual el feminismo toma para sí una tarea ética que enmarca la reformulación de sus postulados políticos:

El principio es el respeto a la diversidad sexual y de género de todas las personas en el marco de los derechos humanos. Se hacen más complejas las vías de transformación, pero a la vez esta nueva dimensión las hace posibles.

Reconocer la dignidad y la integridad de mujeres y hombres de diversas condiciones e identidades, en igualdad, plantea un nuevo mapa habitado por heterosexuales, homosexuales, gays, lesbianas, transgénero, transexuales. Lo que implica revolucionar la organización sexual de género y minar las estructuras binarias patriarcales. (Marcela LAGARDE, 2012, p. 450)

Una definición del sujeto feminista en este sentido, sostiene Lagarde, confluye no solo con las perspectivas políticas que, como los feminismos postestructuralistas, critican el binarismo y la heteronormatividad de género, sino también con la crítica planteada por los feminismos lesbianos, negros y poscoloniales de las estructuras de discriminación y odio étnico y racial que sustentan un orden social profundamente antidemocrático y desigual.

En este sentido, el feminismo no solo busca "acabar con el sexismo, la explotación sexista y la opresión" (bell HOOKS, 2017, p. 21), sino que ha devenido un movimiento político crucial en el nuevo contexto de avance de la violencia clasista, racista y sexista, sea estatal o paraestatal, "en las calles, en las camas y en las casas" como señalaban las feministas chilenas bajo la dictadura en los años 80. El feminismo es una política "para todo el mundo", pero esta ampliación no supone una universalización del sujeto de su política, una operación que el feminismo denuncia desde sus orígenes, sino su transversalización.

Las feministas desafiaron la retórica universalista de los derechos y la ciudadanía, así como la perspectiva humanitaria del paradigma jurídico de individuo abstracto y universal como ideal normativo que caracteriza al pensamiento filosófico-político de la Modernidad. En América Latina, por ejemplo, la apropiación del discurso de los derechos humanos incorporó de a poco una mirada centrada en la diversidad de experiencias de las mujeres en diferentes contextos, así como la construcción de coaliciones que integran de manera creciente dimensiones de género, raza, clase, y promovió agendas colectivas de derechos. Sin embargo, como muestra la historia de los Encuentros Feministas Latinoamericanos y del Caribe (EFLAC) y de los Encuentros de Mujeres en Argentina, la diferencia ha impulsado amargos debates y fracturas, cuya resolución no puede ser sino contextual y efímera (Cecilia OLEA MULEÓN; Virginia VARGAS VALENTE, 1998). ${ }^{5}$

En ese marco general, la transformación de la concepción política del feminismo en América Latina se orienta, según Lagarde, en tres claves de la experiencia de las mujeres: la mismidad, entendida como una ética del cuidado y afirmación del 'yo-misma/o' (empoderamiento), la solidaridad intergenérica, con base en el reconocimiento, la justicia y la igualdad de género; y la sororidad. Voy a detenerme en esta última noción que, a mi entender, delimita de manera específica una política y una ética feministas para esta autora, para confrontar las transformaciones del viaje conceptual que, entre los últimos años 60 y el fin de los 80 , configura la política feminista como algo que también ocurre entre-mujeres. Este vínculo, que para las feministas radicales estadounidenses intensificaba la discordia y la división, Lagarde lo traduce en la forma de una trama afectiva entre pares e intergeneracional que entreteje subjetividad y política.

La politización de los vínculos feministas remite a los límites que deben franquear las

\footnotetext{
${ }^{5}$ Entre otros hitos de la organización y creación de alianzas feministas regionales más conocidos: la Conferencia Mundial del Año Internacional de la Mujer (México, 1975) que inauguró la Década de Naciones Unidas para la Mujer con el debate sobre la desigualdad entre varones y mujeres; las Conferencias Mundiales de Copenhague (1980), Nairobi (1985) y Beijing (1995) que visibilizaron la consigna "los derechos de las mujeres son derechos humanos" y su carácter inalienable, integral e indivisible. Estos hitos acompañaron el despegue de los feminismos en la región en torno a problemáticas como la violencia contra las mujeres y los derechos sexuales y reproductivos, y dieron forma a los "nudos de debate" que los atravesaron, por ejemplo, en el EFLAC desde su inicio en 1981 (Bogotá, Colombia) con la cuestión de la autonomía y la representación.
} 
relaciones entre mujeres en la sociedad patriarcal en que vivimos, pues "trastoca[n] un pilar patriarcal: la prohibición de la alianza de las mujeres y permite enfrentar la enemistad genérica, que patriarcalmente estimula entre las mujeres la competencia, la descalificación y el daño" (LAGARDE, 2012, p. 34). De este modo, recuperando la noción de patriarcado como estructura de dominación inter e intragenéricas que, a su vez puede contener otras formas de diferenciación y dominación, coloca la cuestión de la diferencia y la desconfianza entre las mujeres como uno de los ejes de dicha lógica, junto a la idea de complementariedad entre los sexos y a la esencialización de la función maternal. Esta dificultad de las mujeres para establecer alianzas y pactos de sostén mutuo obstaculiza, según Lagarde, el despliegue de las potencialidades políticas del feminismo.

Para desarmar esta estructura patriarcal, expresada en una misoginia dirigida muchas veces hacia nuestras amigas y aliadas, postula la sororidad como solidaridad política entre mujeres (LAGARDE, 2012, p. 461-492) correspondiente al trabajo político feminista para desarmar cotidianamente todas las instancias en las cuales las mujeres privilegiarían las diferencias y la competencia por el poder por sobre los consensos posibles y el reconocimiento de la diversidad de experiencias de opresión y explotación (LAGARDE, 2009). En este sentido, la sororidad es una práctica afincada en los vínculos próximos y el reconocimiento de la mismidad y las discrepancias, que trasciende las generaciones y se convierte también en una práctica de memoria, al recuperar genealogías de sororas, visibilizando sus acciones y experiencias, y favoreciendo identificaciones transversales fundadas en el respeto a la pluralidad y la creatividad.

El modelo que recupera parcialmente Lagarde es el del affidamento y la reconstrucción de genealogías femeninas desarrolladas por las feministas italianas de fines de los años 70 - que trato en el próximo apartado -, aunque la elección de la noción de sororidad la liga con la de sisterhood de las feministas radicales estadounidenses. Y este es un aspecto que la propia Lagarde intenta problematizar en su propuesta. Me refiero a la cuestión de las diferencias y los desacuerdos, que Lagarde considera como secundarios en el orden de los vínculos feministas, supeditados al imperativo de la solidaridad entre mujeres, lo cual excluye aquellas emociones que separan (la enemistad) y que expresan los estereotipos patriarcales de la rivalidad entre mujeres. Pero el disenso, las rivalidades y las enemistades existen también entre feministas, lo sabemos bien. ¿Cómo podríamos pensar una forma de vinculación específicamente feminista, que exprese a su vez una memoria de las experiencias y una posición política pero que no excluya la emergencia del disenso político, y sobre todo no la traduzca como 'enemistad' interpersonal a ser expulsada de la política feminista?

En su indagación acerca de los vínculos feministas, Ahmed (2018) recupera la propuesta del colectivo Sisters Uncut, un movimiento de acción directa que lucha contra el sexismo, la violencia y el abuso sexuales y los efectos del ajuste estatal neoliberal sobre las vidas de las mujeres en el Reino Unido desde una óptica interseccional. Ante la pregunta acerca de quiénes son 'las mujeres' por las que dice hablar, Sisters Uncut responde desde la organización política de la diferencia y la articulación de las opresiones -"sexismo, racismo, transfobia, capacitismo, clasismo y homofobia"-, una manera de mantener "la categoría de mujeres abierta a las mujeres" (AHMED, 2018, p. 286) considerando aquello que las hermana y conteniendo lo que las diferencia. De este modo, "las mujeres (trans, intersex, cis), [son] todas aquellas que sufren opresión como mujeres (incluidas las personas no binarias y no conformes con el género) y todas aquellas que se identifican como mujeres con el propósito de la organización política" (AHMED, 2018, p. 287).

Una definición como esta, precisa y abierta a la vez, coloca al "sujeto feminista femenino" -histórico, corporizado y localizado (Rosi BRAIDOTTI, 2004, p. 43-47)- ${ }^{6}$ como efecto de un acto contingente y repentino, en la punta de un 'chasquido' (snap) dice Ahmed (2018), sujeto a la aprobación y reconocimiento de las sororas (sisters). Este es quizás un modo de esquivar tanto la representación política identitaria esencializada como las apropiaciones e instrumentalización neoliberal del feminismo, cuyas lógicas desconocen las genealogías afectivas tejidas en las prácticas del activismo feminista.

\section{La práctlca de la dlferencia sexual}

Entre las historias del feminismo occidental, el feminismo italiano ocupa generalmente un lugar al margen de las narraciones hegemónicas, una rareza circunscripta a su contexto nacional que resulta intraducible a las lógicas de las corrientes radicales, socialistas o culturales más conocidas (Teresa DE LAURETIS, 1990; BRAIDOTTI, 2000; María-Milagros RIVERA GARRETAS, 2000; Linda ZERILLI, 2008, p. 187-238; Fina BIRULÉS, 2015, p. 42-49). Si bien la cuestión de la diferencia sexual y la centralidad de la experiencia (femenina) recorren los debates feministas desde que Simone de Beauvoir tratara la "diferencia entre los sexos" (Debra BERGOFFEN, 2003), y luego desde el planteo de las feministas chicanas, lesbianas y negras en los años 70-80 en torno a la diferencia

\footnotetext{
"Braidotti desarrolla la noción de "sujeto feminista femenino" a partir de la propuesta de Teresa de Lauretis, Luce Irigaray y del planteo de las feministas italianas sobre la necesidad de trazar contra-genealogías, en un cruce con la perspectiva postestructuralista (fundamentalmente Gilles Deleuze y Michel Foucault).
} 
entre las mujeres (y las feministas), las feministas italianas retoman estas cuestiones de manera original, aunque sin resolverlas. Retomo aquí algunas de sus propuestas más difundidas sobre la noción de diferencia que es divergente, aunque coetánea, a la emergencia en el feminismo estadounidense. ${ }^{7}$

En un breve recorrido por manifiestos, diarios personales, escritos colectivos y consignas de las feministas italianas durante los años 70 y 80 , surgen de manera problemática la disparidad y las diferencias entre mujeres, así como incomodidades en las mujeres, que juntan y separan al sujeto feminista.

Como buena parte de los escritos producidos por los diferentes colectivos feministas en Italia desde fines de los años '60 (LIBRERÍA DE MUJERES DE MILÁN, 1991), ${ }^{8}$ el 'diario feminista' escrito por Carla Lonzi (1978a) entre 1972-1977 desgrana los días mientras analiza con escalpelo las relaciones con amigas, compañeras y amantes dentro y fuera de los grupos de autoconsciencia del grupo Rivolta Femminile en Milán. En la entrada del 13 de septiembre de 1972 se refiere a la recepción del volumen colectivo Escupamos sobre Hegel en ese grupo:

Hace algún tiempo, cuando todavía había descontento en el grupo y alguien dijo que yo era una líder y que se sentía como delante de un hombre, en realidad me entendían mal, como en el mundo masculino porque no era más masculino, porque no tuve un comportamiento más complaciente y comprensivo de la hermandad [sorellanza], por ejemplo, democrático, humilde, posibilista, transigente [...] Estaba acostumbrada a que no me entendieran y podía no perder el pie, incluso si no seguía adelante. No sabía cuán importante es el reconocimiento porque todavía no lo había "experimentado": así que también con respecto a los demás lo mantuve implícito, me pareció una falta de modestia ofrecerlo. Temía que fuera un gesto presuntuoso [...] Ahora sé qué desencadena darlo y tenerlo. (LONZI, 1978b, p. 80-81).

En otra entrada se lamenta porque, afirma, "En mi vida he tenido admiración o envidia por parte de las mujeres, pero poco afecto y verdadera comprensión. [...] si en el mundo masculino es suficiente para mí el afecto y reconocimiento, en el mundo femenino no me alcanza, me gustaría tener una relación con todas" (15 de enero de 1973).

Podemos preguntarnos si acaso sería posible esta "relación con todas" que deseaba Lonzi, entendida como una forma de reconocimiento que se desligue tanto de las jerarquías como de las diferencias que surgen en las relaciones cotidianas de trabajo, de compañerismo y eróticas, de amistad y de amor entre mujeres. ¿Quién no ha experimentado esta desazón y decepción alguna vez?

Teresa de Lauretis (2000) señala que cuando el feminismo afirma su política en el supuesto de una relación de transparencia entre experiencia y lenguaje, reproduce una representación unificada de la subjetividad femenina y reniega de la particularidad de la experiencia diferenciada del "sujeto feminista femenino", de su sexualidad y su corporalidad, situadas y contingentes. La "paradoja de la mujer" es ser el sujeto "excluido del discurso teórico oficial y, sin embargo, encarcelado dentro del mismo" (DE LAURETIS, 2000, p. 111). Por el contrario, afirma, las feministas italianas se hacen cargo de esta paradoja con su propuesta de instituir un feminismo de la diferencia sexual que sea una práctica política y no una asunción identitaria (DE LAURETIS, 1990). concreta?

¿Pero qué significa esta 'práctica de la diferencia sexual' en la práctica política feminista

En primer lugar, la 'diferencia' que se plantea como constitutiva del sujeto feminista es del orden de lo simbólico, se instala en el nivel de lo psíquico y de lo histórico-social bajo la forma de patrones de identificación regulados por un orden social (patriarcal). De este modo, 'ser mujer' es no ser nunca una mujer específica, porque lo femenino permanece como una experiencia subjetiva e individualizada, sin representación simbólica, que niega en los hechos la existencia social de las mujeres qua mujeres, por lo que las relaciones entre-mujeres solo pueden ser representadas como instrumentales (social e individualmente). Para la filósofa Adriana Cavarero (2000, p. 55-62; 2019) - integrante de la Comunidad Filosófica Diótima en Verona -, el pensamiento de la diferencia sexual debe pensarse en el sentido de una ontología relacional radical que busca forzar el lenguaje de la filosofía hacia un reconocimiento material de la incardinación/corporeidad y de la diferencia sexual como rasgos de la común vulnerabilidad y la codependencia humana. ${ }^{9}$

\footnotetext{
${ }^{7}$ La diferencia sexual también constituye un tema central al pensamiento feminista francés en su versión psicoanalítica y lingüística (Antoinette Fouque e Irigaray) y semiótica textual (Julia Kristeva), algunos de cuyos elementos son retomados por la corriente italiana.

${ }^{8}$ Las primeras agrupaciones feministas en Italia surgen en Milán con la fundación del grupo DEMAU (Desmitificación del Autoritarismo Patriarcal) en 1966, luego el grupo Rivolta Femminile (1970) y la Librería de Mujeres (1975), y se replica en otras ciudades italianas con agrupaciones como la Comunidad Filosófica Diótima (Verona) a comienzos de los 80.

${ }^{9}$ Cavarero postula en diferentes obras una respuesta a la ontología individualista hobbesiana que da primacía a la noción de Sujeto de la Modernidad (soberano de sí), para lo cual articula el pensamiento de Emmanuel Lévinas sobre la vulnerabilidad como elemento constitutivo de la relacionalidad humana en términos éticos, con el tema arendtiano del nacimiento como 'comienzo' y la categoría de 'natalidad' como fundamento de la condición humana de la pluralidad.
} 
En segundo lugar, la diferencia sexual como 'práctica política' supone inscribir simbólicamente su carácter contingente al producir colectivamente una escena política de interacción y puesta en común, "zonas temporariamente autónomas de relaciones entre-mujeres" con una "localización simbólica, como lugar-tiempo provisto de referencias sexuadas femeninas, donde poder estar significativamente" (LIBRERÍA DE LAS MUJERES DE MILÁN, 1991, p. 13-22).

La práctica de la diferencia sexual crea mundo entre las mujeres, constituye el modo bajo el cual las prácticas cotidianas delinean vínculos entre mujeres que conectan vectores horizontales y verticales de la experiencia a través de una serie de figuras políticas (RIVERA GARRETAS, 2000). Por un lado, las prácticas de la autoconciencia que surgen de un "intercambio narrativo recíproco continuo aunque interrumpido, intenso aunque distraído - de nuestras propias historias de vida" (CAVARERO, 2000, 55-66). Como derivación de estas prácticas narrativas de concienciación, el affidamento o política de relaciones de "confianza entre-mujeres" o "amistades políticas narrativas" basadas en una forma de autoridad construida en la interlocución, la escucha y el acompañamiento (Luisa MURARO, 1994)..$^{10}$ Otra figura es la de la construcción de contra-genealogías en/desde el presente, que inscriben simbólicamente las relaciones y emociones que permanecen sin correspondencia en el lenguaje y las prácticas cotidianas de las mujeres, y en particular recuperan la mediación materna con la lengua (Maria Luisa BOCCIA, 1990, p. 190-194). Una última figura que acompaña a las anteriores, la "práctica del hacer," que consiste en la construcción y sostenimiento de espacios autónomos feministas como librerías y centros comunitarios donde las mujeres se encuentran y producen y piensan 'otro' mundo común.

Esta capacidad de reinventarse y transformarse no evitaba, sin embargo, la incomodidad y los "malos sentimientos", como lo expresaba Lonzi en su diario feminista. En el corazón de la práctica de la diferencia sexual emerge el abismo afectivo ante la dificultad de dar lugar a la disparidad (ZERILLI, 2008; AHMED, 2018), el hecho de que las mujeres no somos todas iguales y que, aunque estemos 'juntas,' no necesariamente nos acompañamos.

De Lauretis, por ejemplo, evoca las dificultades para nombrar el lesbianismo por parte de quienes relatan y escriben la historia de las mujeres de la Librería de Milán, que prefieren hablar de "una sexualidad femenil no encarcelada en el deseo masculino" (DE LAURETIS, 1990, p. 111113). El 'riesgo del esencialismo' en el pensamiento de la diferencia sexual al que refiere esta autora emerge como repudio y silencio vergonzante dentro del propio feminismo hacia las experiencias, los afectos y las sexualidades no normativas. Hay también ecos de la "Carta Abierta a Mary Daly" de Lorde (2003) sobre la desigual y asimétrica distribución del dolor y la violencia contra/entre las mujeres por su raza, y en el fondo reverbera la dificultad para recibir el desacuerdo y la indignación de otras feministas ante estas exclusiones, como advierte Ahmed (2014, p. 269).

\section{Notas finales}

Ante los llamados a la acción 'ahora que estamos juntas', las diferencias y los afectos entre feministas continúan desafiando la imaginación política del movimiento en el presente. Una historia de las prácticas afectivas feministas y sus políticas nos permitió evocar lo ecos globales e intergeneracionales, así como las reverberaciones de las desavenencias y los encuentros, la amargura de las rupturas junto con la sororidad, emociones y memorias que resuenan entre sí, produciendo anacronismos virtuosos y nuevas coaliciones.

A partir de algunas imágenes que muestran estas convergencias en las prácticas feministas en nuestra región, se problematizaron nociones feministas como sororidad y hermandad entre mujeres, y se indagó en la dificultad para contener políticamente la diferencia dentro de este movimiento político. La sororidad/hermandad como concepto político feminista, se encuentra lejos de la supuesta 'solidaridad entre mujeres' como 'propia del género', que esencializa una relación feminizada, y permite explorar el paradójico terreno en torno a los vínculos feministas. A diferencia de la solidaridad entre varones (fratria) que parece funcionar más allá de generaciones y géneros, las feministas encontraron que múltiples sobredetermimaciomes atraviesan lo que esperaban fuera una identidad que diera paso a una solidaridad entre las mujeres. La clase, etnia, raza, incluso la edad, marcan ese espacio de relaciones entre mujeres construido en base a experiencias y afectos donde el rencor y la decepción se manifiestan con ironía, como en el poema de Jo Carrillo citado.

Al mismo tiempo que las feministas radicales estadounidenses hacían explotar la sisterhood, las italianas exploraron con el affidamento los ángulos de la políica del sujeto feminista con una apuesta a la disparidad y a la expresión emocional, a fin de producir mediaciones que permitieran enraizar un mundo común que las incluyera a 'todas' y que fundara una base de confianza más allá de las diferencias interpersonales. Las apropiaciones y reformulaciones locales, como las de Lagarde en América Latina, entretejen además políticas de memoria ligadas a la historia social y política de

${ }^{10}$ Muraro retoma críticamente la perspectiva de Hannah Arendt sobre la autoridad, que diferencia la dimensión del dominio ("dar órdenes y mandar"), de la dimensión de la mediación que "hace orden y juzga" en sentido estéticopolítico. 
nuestro continente, un desafío que no elude las contradicciones y tensiones en el momento en que muestra sus diferencias, como se advierte en las acciones de las chilenas de Las Tesis.

Nuestro 'nosotras' es sedimento de esa escucha de reverberaciones en el tiempo, del asombro ante el dolor que compartimos sin apropriarnos porque nos diferencia. Los vínculos feministas y con el feminismo surgen de ese magma en cada presente, y cada vez se enfrentan al desafío de impedir y luchar contra la instrumentalización del feminismo para lo que sea. Cada vez que la diferencia surja como ruptura, el feminismo debería preguntarse '¿Quiénes podemos llegar a ser estas feministas que somos?'

\section{Referencias}

AA.W. "Feminismo sin fronteras. \#8M". Revista Bordes, n. 12, p. 75-87, 23 mayo 2019. Disponible en https://publicaciones.unpaz.edu.ar/OJS/index.php/bordes/article/view/447. Acceso el 25/09/2019.

AHMED, Sara. La política cultural de las emociones. México: UNAM, 2014.

AHMED, Sara. Vivir una vida feminista. Barcelona: Edicions Bellaterra, 2018.

ÁlVAREZ, Sonia. "Feminismos en movimiento, feminismos en protesta". Revista Punto Género [online]. Santiago de Chile, n. 11, p. 73-102, junio. 2019. DOI: 10.5354/0719-0417.2019.53881. Acceso el 10/10/2019.

BERGOFFEN, Debra. "Failed Friendship, Forgotten Genealogies: Simone de Beauvoir and Luce Irigaray". Journal of French and Francophone Philosophy, v. 13, n. 1, p. 16-31, mar. 2003. Disponible en http://jffp.pitt.edu/ojs/index.php/jffp/article/view/436. Acceso el 10/10/2019.

BIRULÉS, Fina. Entreactos. En torno a la política, el feminismo y el pensamiento. Madrid: Katz. 2015.

BOCCIA, María Luisa. L'lo in rivolta. Vissuto e pensiero di Carla Lonzi. Milán: Tartaruga. 1990.

BRAIDOTII, Rosi. "La diferencia sexual como proyecto político nómade”. In Sujetos nómades. Buenos Aires: Paidós, 2000. p. 165-205.

BRAIDOTI, Rosi. "Sobre el sujeto feminista femenino o desde el 'sí mismo-mujer' hasta el 'otro mujer'”. In: Feminismo, diferencia sexual y subjetividad nómade. Barcelona: Gedisa, 2004. p. 33-54.

BROWN, Wendy. El pueblo sin atributos. La secreta revolución del neoliberalismo. Barcelona: Malpaso Ediciones, 2015.

BROWNE, Victoria. Feminism, Time, and nonlinear History. A polytemporal Approach. New York: Palgrave MacMillan, 2014.

CARNEIRO, Sueli. "Mulheres em movimento". In: Escritos de uma vida. São Paulo: Pólen Livros, 2019.

CARRILLO, Jo. "Y cuando se vayan, llévense sus retratos". In: MORAGA, Cherrie; CASTILLO, Ana (Eds.). Esta puente, mi espalda. Voces de mujeres tercermundistas en los Estados Unidos. San Francisco: Editorial Ismo. 1988.

CAVARERO, Adriana. Relating narratives. Storytelling and selfhood, Routledge: New York. 2000.

CAVARERO, Adriana. "Inclinaciones desequilibradas". Papeles del CEIC, v. 2, papel 21 1, p. 1-12. Disponible en http://dx.doi.org/10.1387/pceic.20878. Acceso el 10/1 1/2019.

CELIBERTI, Lilian. "Desatar, desanudar... reanudar". Revista Estudos de Sociologia, Araraquara, v. 20, n. 39, p. 291-308, 2015. Disponible en https://periodicos.fclar.unesp.br/estudos/article/view/ 7554. Acceso el 10/10/2019.

CHEJTER, Silvia (Ed.). "Feminismo por Feministas". Revista Travesías, Año 4, n. 5, octubre 1996.

COLECTIVO NI UNA MENOS. Llamamiento al Paro Feminista 8M 2019, martes 8 de enero de 2019. Disponible en http://niunamenos.org.ar/manifiestos/lamamiento-al-paro-feminista-8m-2019/. Acceso el 10/10/2019.

DA SILVA, Cidinha. "Feminismo negro. De onde viemos: aproximações de uma memória". In: Explosão Feminista: arte, cultura, política e universidade. São Paulo: Companhia das Letras, 2018. p. 252260.

DE LAURETIS, Teresa. "La esencia del triángulo, o tomarse en serio los riesgos del esencialismo: teoría 
feminista en Italia, los E. U. A. y Gran Bretaña". Debate Feminista, México, v. 2, p. 77-115, septiembre 1990.

DE LAURETIS, Teresa. Diferencias. Etapas de un camino a través del feminismo. Madrid: Horas y horas, 2000.

ECHOLS, Alice. "Daring to be bad": radical feminism in America, 1967-75. Minneapolis: University of Minnesota Press. 1989.

Página 12. "El plus de castigo por ser mujeres". Suplemento Rosario 12, 13 de septiembre 2018. Disponible en https://www.pagina12.com.ar/141764-el-plus-de-castigo-por-ser-mujeres. Acceso el 10/10/2019.

FOLLEGATI, Luna. "El constante aparecer del movimiento feminista. Reflexiones desde la contingencia". In: ZERÁN CHELECH, Faride. Mayo feminista. La rebelión contra el patriarcado. Santiago de Chile: LOM, 2018. p. 77-90.

HEMMINGS, Clare. La gramática política de la teoría feminista: ¿por qué las historias importan? Buenos Aires: Prometeo Libros, 2018.

HOOKS, bell. El feminismo es para todo el mundo. Buenos Aires: Traficantes de Sueños, 2017.

LAGARDE, Marcela. "Enemistad y sororidad entre mujeres: hacia una nueva cultura feminista". In: EI feminismo en mi vida. Hitos, claves y utopías, México: Instituto de las Mujeres del Distrito Federal. 2012, p. 461-492. Disponible en www.inmujeres.df.gob.mx. Acceso el 10/10/2019.

LAGARDE, Marcela. "Sororidad". In: GAMBA, Susana (coord.), Diccionario de estudios de género y feminismos. Buenos Aires: Biblos. 2009. p. 305-311.

LIBRERÍA DE MUJERES DE MILÁN. No creas tener derechos. La generación de la libertad femenina en las ideas y vivencias de un grupo de mujeres. Madrid: Horas y Horas, 1991.

LONZI, Carla. Escupamos sobre Hegel y otros escritos sobre Liberación Femenina. Buenos Aires: La Pléyade. 1978.

LONZI, Carla. Taci, anzi parla. Diario di una feminista. Milán: Scritti di Rivolta Femminile, 1978.

LORDE, Audre. Zami una biomitografía. Una nueva forma de escribir mi nombre. Madrid: Horas y Horas, 2009.

LORDE, Audre. "Carta abierta a Mary Daly". In: La hermana, la extranjera. Artículos y conferencias. Madrid: Horas y horas, 2003. p. 57-64.

MEMORIA ABIERTA. "Y nadie quería saber". Relatos sobre violencia contra las mujeres en el terrorismo de Estado. Buenos Aires: Memoria Abierta, 2012.

MEMORIA ABIERTA, Testimonio de Stella Hernández, Rosario (Santa Fe). Buenos Aires: Memoria Abierta. 28 de octubre de 2011.

MOHANTY, Chandra T. Feminism without Borders. Decolonizing Theory, Practicing Solidarity. Durham \& London: Duke University Press, 2003.

MURARO, Luisa. El orden simbólico de la madre, Madrid: Ed. Horas y Horas, 1994.

OBERTI, Alejandra. "El desafío del encuentro: articulaciones entre feminismos y movimiento de derechos humanos" (Comunicación oral). In: JORNADAS NACIONALES DE HISTORIA DE LAS MUJERES CONGRESO IBEROAMERICANO DE ESTUDIOS DE GÉNERO, XIV y IX, 29 de al 1 de agosto 2019, Mar del Plata, UNMDP. Disponible en https://fh.mdp.edu.ar/encuentros/index.php/historiadelasmujeres/index/ pages/view/mesa73. Acceso el 27/09/2019.

OLEA MULEÓN, Cecilia y VARGAS VALENTE, Virginia. "Los nudos de la región". In: OLEA MAULEÓN, Cecilia (Comp.). Encuentros, (Des) Encuentros y Búsquedas: El Movimiento Feminista en América Latina. Lima: Ediciones Flora Tristán, 1998. p. 139-172.

REAL ACADEMIA ESPAÑOLA. "Sororidad". In: Diccionario de la lengua española. Madrid. 2019. Disponible en https://dle.rae.es/sororidad. Acesso el 10/10/2019. 
RIVERA GARRETAS, María-Milagros. "El feminismo de la diferencia sexual: partir de sí", Revista GénEr@\&B\&s, Colima, v. 8, n. 22, p. 5-10, 2000.

SARACHILD, Kathie. "A Program for Feminist 'Consciousness-raising'”. In: Notes from the Second Year: Women's Liberation, 1970, p.78-80. Disponible en https://repository.duke.edu/dc/wlmpc/wlmms010 39. Acceso el 03/10/2017.

SARTI, Cynthia A. "O feminismo brasileiro desde os anos 1970: revisitando uma trajetória". Revista Estudos Feministas, Florianópolis, v. 12, n. 2, p. 35-50, maio-agosto 2004. Disponible en http:// www.scielo.br/pdf/ref/v12n2/23959.pdf. Acceso el 10/10/2019.

SCOTT, Joan W. Las mujeres y los derechos del hombre: feminismo y sufragio en Francia, 17891944. Buenos Aires: Siglo Veintiuno Editores, 2012.

SCOTT, Joan W. The Fantasy of Feminist History. Durham and London: Duke University Press, 2011.

SNITOW, Ann. "A Gender Diary". In: The feminism of uncertainty: a gender diary. Durham and London: Duke University Press, 2015. p. 21-58.

TARDUCCI, Mónica; TREBISACCE, Catalina; GRAMMÁTICO, Karin. Cuando el feminismo era mala palabra. Algunas experiencias del feminismo porteño. Buenos Aires: Espacio Editorial, 2019.

VACAREZZA, Nayla Luz. "El pañuelo verde. Legados políticos, repertorios afectivos y derivas transcordilleranas de un símbolo de la lucha por el aborto legal y libre" (Comunicación oral). In: JORNADAS NACIONALES DE HISTORIA DE LAS MUJERES CONGRESO IBEROAMERICANO DE ESTUDIOS DE GÉNERO, XIV Y IX, 29 de al 1 de agosto 2019, Mar del Plata, UNMDP. Disponible en https://fh.mdp.edu.ar/ encuentros/index.php/historiadelasmujeres/index/pages/view/mesa73 Acceso 27/09/2019.

ZERILLI, Linda M. G. El feminismo y el abismo de la libertad. Buenos Aires: FCE, 2008.

Claudia Andrea Bacci (cabacci@gmail.com) es socióloga (2000) y Magister en Investigación en Ciencias Sociales (2010) por la Universidad de Buenos Aires donde se desempeña como Profesora en la Carrera de Sociología (teoría social y de género, violencia, sexismo y derechos humanos). Su trabajo más reciente articula los estudios de memoria y de género y se enfoca en la relación entre testimonio y política en las escenas judicial y de memorias sobre el pasado reciente en la Arcenting

\section{COMO CITAR ESTE ARTíCULO, DE ACUERDO CON LAS NORMAS DE LA REVISTA:}

$\mathrm{BACCl}$, Claudia Andrea. "Ahora que estamos juntas: memorias, políticas y emociones feministas". Revista Estudos Feministas, Florianópolis, v. 28, n. 2, e72446, 2020.

CONTRIBUCIÓN DE AUTORÍA

No se aplica.

FINANCIACIÓN

Proyecto PICT 2014-1922 "La tradición filosófica y política desde la perspectiva de Hannah Arendt. Lecturas modernas y reapropiaciones contemporáneas" (Agencia Nacional de Promoción Científica, Argentina). Proyecto UBACyT 20020170200184 "Pasado/Presente. Afectos, testimonios y archivos en la cultura argentina contemporánea" (Instituto Interdisciplinario de Estudios de Género/UBA, Argentina).

CONSENTIMIENTO DE USO DE IMAGEN

No se aplica.

APROBACIÓN DE COMITÉ DE ÉTICA EN INVESTIGACIÓN

No se aplica.

CONFLICTO DE INTERESES

No se aplica.

LICENCIA DE USO

Este artículo está licenciado bajo la Licencia Creative Commons CC-BY Internacional. Con esta licencia se puede compartir, adaptar, crear material para cualquier objetivo, siempre que se le atribuya la autoría. 
HISTORIAL

Recibido el 25/03/2020

Aprobado el 16/04/2020 